\title{
Reproduction in water buffalo: comparative aspects and implications for management
}

\author{
B. M. A. Oswin Perera \\ Animal Production and Health Section, Joint FAO/LAEA Division of Nuclear Techniques in \\ Agriculture, International Atomic Energy/Agency, PO Box 100, A-1400 Vienna, Austria
}

\begin{abstract}
The domestic buffalo occupies an important niche in many ecologically disadvantaged agricultural systems, providing milk, meat and draught power. Although buffalo can adapt to harsh environments and live on low quality forage, their reproductive efficiency is often compromised by such conditions. Climatic stress depresses ovarian cyclicity, oestrous expression and conception rates. Poor nutrition, usually related to seasonal fluctuations in availability and quality of feed, delays puberty and increases the duration of postpartum anoestrus. Management factors such as the system of grazing (free, tethered or none) and sucking by calves (restricted or ad libitum) also modulate reproductive functions. Finally, the skills and capabilities of farmers as well as the quality of support services such as artificial insemination and disease control also influence fertility. The relative importance of these factors vary greatly depending on ecological conditions and production systems. Improvement of reproductive efficiency therefore requires the identification of specific limiting factors under a given situation and the development and field testing of strategies for improvements and interventions that are sustainable with available local resources. The application of modern reproductive technologies in buffaloes requires an appreciation of their biology and reproductive physiology as well as the potentials and limitations under each specific production system.
\end{abstract}

\section{Introduction}

The domestic water buffalo (Bubalus bubalis) is an important livestock resource in many countries of Asia, the Meditertanean region and Latin America. The world population of buffaloes is estimated to be $140-150 \times 10^{6}$, of which over $90 \%$ are in developing countries. They have been classified into three main types: river, swamp and Mediterranean (Cockrill, 1974).

The buffalo has been traditionally regarded as a poor breeder because in most conditions under which it is usually raised, which are small-holder farming systems in harsh environments with minimal managerial inputs, they have low fertility (Bhattacharya, 1974). This is manifested mainly as late maturity, long postpartum anoestrus, poor expression of oestrous signs, low conception rates (CR) and long calving intervals (CI). However, studies on feral buffaloes in Australia (Tulloch, 1979), as well as on domestic buffaloes in Pakistan (Usmani et al., 1985), Sri Lanka (Perera et al., 1987) and Brazil (Vale et al., 1990) prove that they can have excellent fertility provided that genotypes are matched to the environment and they are managed and fed properly. A unique advantage of the buffalo is its ability to utilize poor forages more efficiently than do cattle (Sebastian et al., 1970). However, the buffalo cannot dissipate heat as efficiently as cattle through physiological methods such as sweating (Ranawana et al., 1984) and has therefore developed the strategy of wallowing in order to maintain homeostasis when environmental temperature is high. 
In early attempts to improve fertility of buffaloes through reproductive technologies such as artificial insemination (AI), oestrous synchronization and embryo transfer, researchers and livestock personnel often presumed that the reproductive biology of the buffalo was identical to that of cattle. This direct extrapolation of methods resulted in poor fertility, particularly when applied under practical farming conditions. More recently, however, the application of modern research technologies has provided valuable insights into the physiology of buffaloes, and this has allowed a more informed approach to the improvement of their reproductive performance.

Comparative aspects of reproduction in cattle and buffaloes have been the subject of comprehensive reviews a decade ago (Dobson and Kamonpatana, 1986; Jainudeen and Hafez, 1987) and subsequent advances in knowledge on buffalo reproduction have been reviewed by Madan et al. (1996); Vale (1997); and Zicarelli (1997). This review will therefore not attempt to cover all aspects of buffalo reproduction. Its main objectives are to: (i) selectively review certain aspects that are important from the viewpoint of practical field applications under prevailing farming systems; (ii) highlight some important species differences compared with cattle; and (iii) discuss opportunities and constraints to the application of modern reproductive technologies for improving buffalo production in situations in which they make an important economic contribution.

\section{Buffalo Farming Systems}

Systems of buffalo production vary widely through the different regions of the world (Mahadevan, 1992) and are determined by factors such as climate (tropical or temperate, humid or arid), type of operation (small or large farm, subsistence or commercial), integration with cropping systems (rainfed or irrigated, annual or perennial) and the primary purpose (milk, meat, draught, capital or mixed). Because the potential for application of improved reproductive technologies is dictated by the characteristics and available resources in specific production systems (Perera, 1994), a brief overview of types of buffalo and husbandry conditions in different regions of the world is provided.

In South Asia, most buffaloes are of the river type and are raised mainly by small-holders in subsistence or semi-commercial farms. Dairy breeds such as Murrah, Surti and Nili-Ravi are kept in irrigated and rain-fed intensive cropping areas under confinement, with stall-feeding on cut grass, crop residues and concentrates. In the less intensively farmed areas they are managed extensively, with grazing on communal lands supplemented by crop residues and byproducts. Urban areas around major cities have large herds raised purely for milk production under a unique intensive system, in which high producing cows are brought in, kept for the duration of their lactation and disposed of.

In East and South-East Asia, the swamp type predominates and is reared mainly on small farms with integrated crop-livestock husbandry. The major usage is for draught associated with rice cultivation. The buffalo is considered a sign of wealth and status in many communities, provides companionship to the family and is featured in religious and cultural events. The production systems are mostly extensive, with free or tethered grazing on communal lands and little or no supplementary feeding except perhaps rice straw and leguminous tree leaves during periods of drought.

Most of the buffalo in North Africa and the Middle East are of the river and Mediterranean types and are concentrated around the Nile delta. They are kept mainly by small-holders for producing milk and eventually beef. There are a few commercial operations in urban areas, for specialized production of milk and beef under intensive systems. In Europe buffaloes of the Mediterranean type predominate and are kept on large commercial farms under semi-intensive or intensive systems for milk and meat production.

Buffalo production has expanded markedly over the past decade in the Latin American region. Buffalo are raised mainly in areas with poor soil or periodic flooding and are able to thrive in conditions that even Zebu cattle cannot cope with. Production systems vary depending on the purpose, but herd sizes are generally large compared with those in other regions. Beef production is usually under extensive conditions while milk production is more intensively managed, but dualpurpose systems are also found. 


\section{Reproduction in Female Water Buffalo}

\section{Anatomical aspects}

The mature ovaries are smaller in water buffalo than in cattle, and weigh about $2.5 \mathrm{~g}$ when inactive and $4 \mathrm{~g}$ when active; there are fewer primordial and tertiary follicles (Danell, 1987; Zicarelli, 1997). During the oestrous cycle follicular growth occurs in two waves as in cattle. Mature Graafian follicles rarely exceed $8 \mathrm{~mm}$ in diameter (Jainudeen et al., 1983), whereas in cattle they often exceed $12 \mathrm{~mm}$. Mature follicles tend to protrude from the surface of the ovary and can be mistaken for an early corpus luteum when palpated per rectum. The corpus luteum is soft at first and becomes larger and firmer by mid-cycle. It is smaller than in cattle, and often does not protrude markedly from the surface of the ovary and it sometimes lacks a clear crown. These attributes make accurate identification of ovarian structures by rectal palpation in buffaloes more difficult than they are in cattle (Sharifuddin and Jainudeen, 1983; Perera et al., 1987). It is therefore necessary that veterinarians wishing to gain proficiency in ovarian palpation of buffaloes subsequently visualize the palpated structures using ultrasonography or laparoscopy or, in animals destined for slaughter, post mortem.

The uterus and cervix of water buffaloes are smaller than they are in cattle and lie wholly within the pelvic cavity and the uterus is usually tightly coiled (Perera et al., 1977). The cervical canal is narrower than in cattle and presents a greater challenge for AI technicians to negotiate with the insemination gun or pipette, particularly in heifers.

\section{Puberty}

Buffalo heifers usually attain puberty when they reach about $55-60 \%$ of their adult body weight, but the age at which they attain puberty can be highly variable, ranging from 18 to 46 months (Bhattacharya, 1974). The factors that influence this are genotype, nutrition, management, social environment, climate, year or season of birth, and diseases. The body weight at which puberty is attained is strongly influenced by genotype and is about $200-300 \mathrm{~kg}$ for swamp types and $250-400 \mathrm{~kg}$ for river types. Although buffaloes attain puberty later than cattle, they have a longer reproductive life, which tends to compensate for this early economic disadvantage.

The best methods for advancing the age at puberty are provision of good management and feeding from birth, alleviation of heat stress where necessary and control of parasites and diseases.

\section{Oestrous cycle}

The mean duration of the ovarian cycle in water buffaloes is similar to that in cattle. However, there is greater variability and a higher incidence of both abnormally short and long cycles. This finding can be attributed to various factors, including adverse environmental conditions and nutrition (Kaur and Arora, 1982; Kanai and Shimizu, 1984). There is considerable variability in the duration of oestrus (Luktuke and Ahuja, 1961; Danell, 1987), timing of ovulation (Kanai et al., 1990) and the interval from peak LH concentration to ovulation (Zicarelli et al., 1997) (Table 1). Moioli et al. (1998) showed that the interval from peak LH concentration to ovulation was $25 \pm 13 \mathrm{~h}$ in animals that conceived after AI, while it was $46 \pm 18 \mathrm{~h}$ in those that did not. Clearly, this high variability imposes major limitations to the wider use of AI, but is probably not of major consequence in natural breeding systems.

Another common abnormality in the ovarian cycle and ovarian activity in buffaloes is anoestrus or acyclicity as discussed later in the section on the postpartum period. Cystic ovaries, either follicular or luteal, are rare in buffaloes.

\section{Oestrous behaviour and external manifestations}

Buffalo farmers and researchers agree that detection of oestrus in buffalo is more difficult than it is in cattle and this has been a major impediment to the use of AI and other improved breeding 
Table 1. Duration and timing of events associated with the oestrous cycle in buffaloes

\begin{tabular}{lcr}
\hline Characteristic & Mean & Range \\
\hline Duration of oestrous cycle (days) & 21 & $17-26$ \\
Duration of oestrus (h) & 20 & $5-27$ \\
Onset of oestrus to ovulation (h) & 34 & $24-48$ \\
Duration of LH surge (h) & 10 & $7-12$ \\
LH peak to ovulation (h) & 27 & $12-60$ \\
End of oestrus to ovulation (h) & 14 & $6-21$ \\
\hline
\end{tabular}

(Sources: Luktuke and Ahuja, 1961; Danell, 1987; Jainudeen and Hafez, 1987; Kanai et al, 1990; Zicarelli et al., 1997).

techniques. Homosexual activity is not as common as it is in cattle: only about $20 \%$ of females exhibit it (Danell, 1987; Vale et al., 1990; Barkawi et al., 1993). In a herd, the females that are higher in the social dominance order tend to exhibit such behaviour. Other behavioural signs include restlessness, bellowing and frequent voiding of small quantities of urine (Danell, 1987; Vale et al., 1990), but these behaviours are not consistently exhibited in most animals. During periods of high ambient temperature, the duration of oestrus may be shorter and the signs exhibited only during the night or early morning.

Externally detectable physical changes around the time of oestrus include swelling of the vulva and reddening of the vestibular mucosa (Kanai and Shimizu, 1984; Danell, 1987). Swelling of the vulva results in effacement of the horizontal wrinkles that are present on its external surface and this, together with vestibular reddening, can be detected by regular examination of individual animals under confined conditions. Mucus secreted from the cervix during oestrus is less copious than it is in cattle, and does not usually hang as strands from the vulva, but tends to accumulate on the floor of the vagina and be discharged either when the animal is lying down (Perera et al., 1977) or with the urine (Kanai et al., 1990). Thus in buffaloes that are housed or tethered, a good practice is to examine the floor near the rear of the animal each morning and evening for signs of mucus. Studies using intravaginal probes to detect either electrical conductivity or resistance (Narasimha Rao and Venkataramiah, 1989) appeared promising as aids to defection of oestrus, but their applicability under practical farming situations has not been reported subsequently.

Improvement in the detection of oestrus needs education and motivation of farmers, proper identification and records for individual animals and regular close observation for the occurrence of the behavioural and physical signs described above. In many conditions the main method of detection of oestrus is the use of teaser animals such as vasectomized bulls.

\section{Endocrinology}

The changes occurring in the main reproductive hormones during the oestrous cycle, pregnancy, parturition and the postpartum period are now well documented for both river and swamp buffaloes (see Dobson and Kamonpatana, 1986; Jaiundeen and Hafez, 1987).

Progesterone. The temporal changes of progesterone in blood and milk during the ovarian cycle are similar to those in cattle, but the concentration of progesterone is lower, particularly in swamp buffaloes (Kamonpatana et al., 1979; Kanai and Shimizu, 1984; Perera et al., 1987). In river buffaloes, the concentrations are higher than those in swamp buffaloes but still below those in cattle (Danell, 1987; Chohan et al., 1992). In both types of buffalo, the concentration of progesterone in milk parallels that in blood; the concentrations of progesterone in whole milk are four to six times higher than in blood. Concentrations of progesterone in skim (defatted) milk are similar to or slightly lower than those in blood. The main practical application of the progesterone assay is in discriminating between the presence and absence of a corpus luteum, which can be used for monitoring the onset of puberty 
and postpartum ovarian activity, for diagnosis of absence of pregnancy and for investigation of infertility (Perera and Abeyratne, 1979; Garcia et al., 1995). However, given the variability in concentrations of progesterone in buffaloes that are attributable to genotype and sampling procedures, it is necessary that each laboratory establishes standardized methods as well as the levels of discrimination used for diagnosing the presence or absence of luteal function.

Oestradiol. Results from oestradiol measurements in buffaloes are difficult to interpret because of variations in assay methods and limitations of assay sensitivity. In general, concentrations of oestradiol during the follicular phase of the ovarian cycle appear to be relatively lower than they are in cattle (Batra and Pandey, 1982; Kanai and Shimizu, 1984; Avenell et al., 1985) and this may be a reason for the lower intensity of oestrous signs exhibited by buffaloes (Zicarelli, 1997).

Gonadotrophins, Owing to the lack of availability of purified LH and FSH from buffaloes, most studies have relied on heterologous assays with results calculated against a bovine standard. The available data indicate that the temporal pattern of both LH and FSH in buffaloes is basically similar to that in cattle (Avenell et al., 1985; Kanai et al., 1990); a preovulatory LH surge occurs on the day of oestrus and lasts for $7-12 \mathrm{~h}$.

\section{Pregnancy}

The fertilized ovum reaches the uterus by day $4-5$ after oestrus and the blastocyst hatches by day 6-8, the latter event occurring 2-3 days earlier than in cattle (Jainudeen, 1990). However, subsequent development of the conceptus and its features that are palpable per rectum occur at comparatively later gestational ages than in cattle. This appears to be related to the longer duration of gestation in the buffalo, in which it ranges from 300 to 330 days (Perera and de Silva, 1985).

\section{Dingnosis of pregnancy}

Clinical methods for pregnancy diagnosis include rectal palpation and ultrasonography, while the main laboratory methods are based on measurement of progesterone or pregnancy-specific protein B (PSPB). The techniques are basically similar to those used routinely in cattle.

Rectal palpation. Owing to the longer gestation in buffalo, each palpable feature is first discernible about 2-4 weeks later during pregnancy than it is in cattle (Perera, unpublished). Enlargement of the gravid uterine horn and thinning of the uterine wall can be detected in heifers at about 35 days and in cows at 40 days. Presence of fluid and the amniotic vesicle are usually palpable by $40-50$ days, when slipping of fetal membranes is also possible. By 60 days the gravid horn is nearly double the diameter of the non-gravid horn but usually the uterus is still within the pelvic cavity. The stage of pregnancy at which it descends to the abdomen, as well as the disposition of the fetus within the pelvis and abdomen, are more variable than they are in cattle. This appears to be influenced by the degree of rumen fill by altering the space available within the abdomen. The fetus can usually be ballotted from the fourth to the sixth months of gestation and can be directly palpated thereafter until term. Development of fremitus in the middle uterine arteries on the gravid and nongravid sides occurs relatively later than it does in cattle. There is a greater tendency for buffaloes to resist palpation and to strain when the arm is in the rectum, so adequate restraint of the animal and patience are required.

Ultrasonograplyy. As in cattle, the most practical type of instrument is one based on real-time Bmode ultrasonography, equipped with an intra-rectal transducer operating at 5.0 or $7.5 \mathrm{MHz}$. The embryonic vesicle (non-echogenic) and the embryo proper (echogenic) can be imaged by about 19-21 days after mating. The heartbeat of the embryo is discernible at 30-35 days and structures such as the allantois, amnion, spinal cord and limbs can be imaged at 35-40 days (Perera, unpublished). The stage of gestation can be deduced from the heart rate and the length of the embryo.

Hormone assay. Absence of pregnancy can be diagnosed by measuring progesterone in blood or milk samples collected at 20-23 days after mating with an accuracy approaching $100 \%$, whereas 
the accuracy for diagnosing pregnancy is only $65-80 \%$ (Perera et al., 1980). Early diagnosis of nonpregnancy has particular advantages in buffaloes in which returns to oestrus are more easily missed, in that animals requiring closer attention can be identified and appropriate action taken. For positive confirmation of pregnancy the measurement of PSPB in blood can be performed from $30-40$ days onwards (Debenedettia et al., 1997).

\section{Parturition}

The process, stages and duration of parturition in buffaloes are similar to those in cattle. Complications such as dystocia are less common in buffaloes but, if they do occur, are more severe and difficult to correct than they are in cattle (L. N. A. de Silva, personal communication). The changes occurring in hormones such as progesterone, oestrone and the main metabolite of prostaglandin $\mathrm{F}_{2 \alpha}$ (PGFM) around the period of parturition are similar to those in cattle (Perera el al., 1981).

\section{Postpartum period}

Uterine involution. Uterine involution is usually completed by $25-35$ days after calving (Jainuden and Hafez, 1987; Perera et al, 1987), which is similar to the period required in cattle. The stimulus of suckling has been shown to shorten the involution time (Usmani et al., 1990). Postpartum infections and complications are generally uncommon in buffaloes, except in certain management conditions in which poor hygiene in the calving environment, wallowing in contaminated water or prevalence of specific infections of the reproductive tract lead to endometritis and pyometra.

Ovarian activity. The period of postpartum anoestrus or acyclicity is usually longer in buffaloes than in cattle under comparative management conditions (see Dobson and Kamonpatana, 1986; Jainudeen and Hafez, 1987). Studies in Sri Lanka (de Silva et al., 1985) have shown that indigenous buffaloes raised by village farmers have a highly variable period of postpartum anoestrus, depending on the management system. In one traditional system where they were raised under free-grazing conditions with abundant natural feed, restricted suckling and presence of intact bulls, ovarian activity commenced by $30-60$ days after calving and most cows conceived at the first ovulation, resulting in calving intervals of 12-13 months (Perera et al., 1987). However, in a similar system but with poor feed availability and free suckling by the calves, ovarian activity was delayed until 150-200 days after calving, resulting in calving intervals of 18-20 months (Perera et al., 1988). In both of these situations the incidence of short ovarian cycles at the commencement of ovarian activity was about $12 \%$, which is much lower than that observed in dairy cattle. However, dairy buffaloes under confined management systems have a much higher incidence of short luteal phases before the first oestrus (Agarwal and Purbey, 1983; Usmani et al., 1990). Recent studies (Zicarelli, 1997; Moioli et al., 1998) indicate that the presence of bulls has a biostimulatory effect on postpartum. ovarian activity of buffalo cows, which can reduce cyclic irregularities and also advance the time of ovulation.

Buffalo cows that are freely suckled by their calves have a longer period of postpartum anoestrus than do those that are subjected to limited or no sucking (Mohan et al., 1990; Tiwari and Pathak, 1995). In milked dairy buffaloes, sucking for $2 \mathrm{~min}$ twice a day delays follicular development, first rise in progesterone, first palpable corpus luteum and first oestrus (Usmani et al., 1990). A study on indigenous buffaloes in Sri Lanka (Abeygunawardena et al., 1996a) showed that under extensive management systems, in which weaned calves are not provided with supplementary feed, early weaning has adverse effects on their growth and survivability. In contrast, restricted sucking once or twice a day improved pregnancy rates without increasing mortality of calves (Table 2).

Other factors that have important influences on postpartum ovarian activity are climate and nutrition (Ahmed et al., 1981), which are often interrelated in extensive grazing systems (Lundstrom et al., 1982; Kaur and Arora, 1982), and the presence of parasitism and diseases.

Reducing the duration of the postpartum anoestrous period is perhaps the most important consideration in attempts to improve reproductive efficiency of buffaloes. This can be achieved by 
Table 2. Effects of different sucking regimens on pregnancy rates in indigenous buffalo cows at 90 and 150 days postpartum and on mortality of their calves up to 6 months of age

\begin{tabular}{|c|c|c|c|c|}
\hline \multirow[b]{2}{*}{ Sucking regimen } & \multirow[b]{2}{*}{$n$} & \multicolumn{2}{|c|}{ Pregnancy rate (\%) at: } & \multirow{2}{*}{$\begin{array}{c}\text { Calf } \\
\text { deaths } \\
(\%)\end{array}$} \\
\hline & & 90 days & 150 days & \\
\hline Free sucking (Control) & 74 & 19 & 23 & 5.4 \\
\hline Weaned at 45 days & 11 & 54 & 73 & 55.0 \\
\hline Weaned at 60 days & 16 & 6 & 37 & 31.0 \\
\hline Weaned at 90 days & 18 & 5 & 27 & 33.0 \\
\hline Once per day & 29 & 38 & 59 & 6.8 \\
\hline Twice per day & 22 & 31 & 59 & 4.5 \\
\hline
\end{tabular}

(Data from Abeygunawardena et al., 1996a)

ensuring that the inhibitory effects of climate, management, nutrition and diseases discussed above are eliminated or ameliorated. In small-holder systems this demands a holistic approach from researchers and livestock support services to develop and transfer a package of appropriate technologies to farmers through close interaction with them (Abeygunawardena et al., 1996b). The use of hormones and other therapeutic interventions to overcome anoestrus are unlikely to be successful unless these basic constraints are resolved.

Endocrinology. LH secretion in buffaloes remains low during the early postpartum period and episodic pulses become detectable a few weeks before ovarian activity commences (Mohan et al., 1990). The timing of this change depends on the factors mentioned above and, for example, occurs earlier in animals that are subjected to better nutrition or restricted suckling than in those under poor nutrition or free sucking. Progesterone profiles during the postpartum period reflect luteal function (Perera, 1980; Jainudeen et al., 1983) and are useful for monitoring ovarian activity, detecting causes of poor reproductive efficiency, improving reproductive management and comparing the responses to interventions aimed at improving fertility (Perera et al., 1984; Garcia et al., 1995).

\section{Measurement of reproductive efficiency}

For assessing reproductive efficiency, of an individual, herd or population, reproductive indices commonly used in cattle, for example interval from calving to first oestrus and conception, conception rate to first or all services, overall pregnancy rate, services per conception, calving rate and calving interval, are applied to buffaloes. Values for these characteristics available from different countries for various buffalo genotypes and their crosses, and under varying agro-climatic and management conditions, confirm the highly variable nature of such measures depending on the specific situation (Jainudeen and Hafez, 1987).

Therefore, in setting acceptability criteria and standards for reproductive indices it is important to consider these factors as well as the main purpose for which the animals are raised. In modern dairy cattle systems, the optimum calving interval is considered to be one year and, since the average duration of gestation is 280 days, cows must become pregnant by 85 days after calving. With the longer duration of gestation of 300-330 days in buffaloes a one year calving interval is often impossible to achieve. Furthermore, although a short calving interval is desirable in purely dairy systems, it may not be advantageous in situations in which draught power and other outputs are also important. Indeed, in conditions with limited and highly seasonal feed resources buffaloes may calve only every other year. Attempts to reduce this interval could result in losses due to deaths of calves born during unfavourable seasons or to low survivability of the dam. Thus a more realistic and achievable set of criteria needs to be developed for such production systems, based on the optimum economic benefits that can be derived by farmers using the available resources in a sustainable manner. 


\section{Reproduction in Male Water Buffalo}

\section{Puberty and sexual maturily}

The age at puberty is influenced by breed and nutrition, and varies from 18 to 46 months (Jainudeen and Hafez, 1987). The growth of the testis can be assessed by measuring scrotal circumference and is related to body weight and age (Bongso et al., 1984). Cell division in the spermatogenic series commences by about 12 months of age and active spermatogenesis can be detected by 15 months. Fully formed spermatozoa have been detected in the seminiferous tubules by 17-19 months, but the ejaculate contains motile spermatozoa only after 24-30 months of age Jainudeen and $\mathrm{Hafez}_{,}$1987). Thus there appears to be a longer period of delay in buffalo than in cattle between the establishment of spermatogenesis in the testis and the appearance of motile spermatozoa in the ejaculate. Sexual maturity or full potential is usually reached about one year after puberty.

\section{The adult male}

Although buffalo bulls can reproduce throughout the year, under certain conditions (as is also the case with buffalo cows) seasonal changes are observed in libido and fertility. In feral or wild buffaloes a period of annual sexual activity similar to the rutting behaviour seen in other wild ungulates is common (Tulloch, 1979). Under domestication these seasonal changes in reproductive functions are less marked and appear to be related to factors such as rainfall through fluctuations in the quality and availability of feed and to temperature and humidity through effects on spermatogenic functions.

The secretion of LH and testosterone is basically similar to that in cattle, with a typical episodic or pulsatile pattern, but with the exception that the concentration of testosterone in blood is significantly lower than it is in cattle (Perera et al., 1979; Ohashi et al., 1996). This has been implicated as a reason for lower libido in buffalo bulls compared with cattle, but requires further study for confirmation.

In many South-East Asian countries, swamp type buffalo cows are mated to improved river type bulls in order to increase milk production while retaining draught ability and climatic adaptability. Since the number of diploid chromosomes in swamp types is 48 whereas it is 50 in river types, the F1 generation will have a proportion of animals with an unbalanced karyotype of 49 chromosomes (Bongso et al., 1983). Such animals can have a higher rate of degeneration of spermatogenic cells and it is therefore important that cross-breeding programmes include the detection and culling of such infertile animals.

\section{Reproductive Technologies}

A major obstacle to improved breeding technologies in buffaloes is the difficulty in detection of oestrus. This has resulted in a much lower usage of AI in buffaloes than in cattle in most countries where both species are raised. Improvement of buffalo production in these countries will undoubtedly benefit from wider use of AI and, where appropriate, other improved breeding technologies. Their rational use, however, requires an understanding of the reproductive functions of this species as well as an appreciation of the potential and limitations of the farming system under which they are to be applied.

\section{Artificial insemination (AI)}

The procedures for collection, evaluation, dilution, preservation and storage of buffalo semen are now well established (see Vale, 1997) and are based mainly on techniques developed for cattle with some modifications, the major differences being in semen diluents, Tris buffers, skim milk and coconut water are more commonly used. 
There is evidence that buffalo spermatozoa subjected to freezing and thawing may have a shorter fertile lifespan inside the female tract than fresh semen (Moioli et al., 1998). Thus accurate detection of oestrus and timing of AI become critical when frozen semen is used and may be one reason for the difference seen in conception rates between $\mathrm{Al}$ and natural mating. Another factor that can contribute to poor conception rates is the narrow cervix of the buffalo, which makes AI more difficult.

The timing of AI commonly used in buffalo is based on the AM/PM rule derived from cattle (that is cows first seen at oestrus in the morning are served in the afternoon and those seen at oestrus in the afternoon are served the next morning). However, as discussed earlier, the temporal relationships between luteolysis, oestrus, LH peak and ovulation are highly variable in buffalo. The optimum time for AI appears to be the end of standing oestrus, when the cow refuses further mounting by teaser males (Moioli et al., 1998), which is later than that in cattle. In most buffalo production systems, however, the use of teaser bulls is not practical. The option may be to inseminate cows about $24 \mathrm{~h}$ after the first detection of signs of oestrus, but this needs further research for confirmation.

Apart from these technical problems, the main obstacles, particularly in less developed countries, are lack of awareness among farmers of the advantages of $\mathrm{AI}$ and inadequacies in infrastructure for efficient delivery of the service.

\section{Synchronization of oestrus}

The methods that have been used to synchronize oestrus in buffaloes are based on those developed in cattle using progestational compounds with or without oestradiol, prostaglandins (PG), or combinations of these (see Perera, 1987). Most studies have shown that the percentage of treated buffalo cows that come into oestrus is acceptable (70-90\%), but the conception rates to AI are about 20-35\% (Pathiraja et al., 1979; Rajamahendran et al., 1980). However, use of natural service can give better results approaching those in cattle.

After withdrawal of exogenous progestagens or treatment with PG the interval to ovulation is more variable than in cattle, resulting in poor fertility when AI is done at predetermined times (Zicarelli et al., 1997). This can be overcome to some extent by doing AI after detection of oestrus, but this defeats one of the main purposes of synchronization, that of being able to dispense with detection of oestrus. There is also the possibility that some ovulating animals will either show very mild or no signs of oestrus and therefore be missed.

The selection of animals to be used in synchronization of oestrus is very important. For regimens using PG the animals must be non-pregnant and cyclic. Ensuring that this occurs is difficult under situations with free range grazing and presence of intact bulls. Use of PG in pregnant animals will cause embryonic death. Although progestagens will not have this effect, the subsequent act of AI can. Animals must also be in good nutritional condition and free from disease. It is also important to ensure that they are not stressed during procedures such as injection of hormones, implantation of devices or AI, particularly under tropical conditions and if they need to be herded together or moved for this purpose. In such situations adequate water, feed and shade must be provided to prevent stress and increase in body temperature which can cause conception failure or early embryonic death. Finally, when there are seasonal differences in breeding activity, synchronization programmes should be scheduled for the more favourable periods when most animals can be expected to be cyclic.

\section{Embryo transfer}

The early experiences in buffaloes with methods of embryo transfer developed for cattle were disappointing but, with recent advances in knowledge on buffalo reproductive physiology, the success rate is clearly improving (Drost et al., 1983; Jainudeen, 1990; Madan et al., 1996; Zicarelli, 1997). In addition, techniques have now been developed in buffaloes for ultrasound-guided ovum pick-up (Boni et al., 1996), in vitro fertilization and embryo culture (Madan et al., 1996). 
In general, the superovulatory responses obtained, recovery of transferable embryos and pregnancy rates in buffaloes have been lower than those in cattle. This has been attributed to differences in ovarian follicular populations, reproductive hormones and general fertility discussed earlier. Given the current success rates, this technology is likely to be applicable only under specific situations for improving buffalo production. Two such opportunities might be in providing the alternative of importing frozen embryos instead of live animals when nucleus breeding stocks need to be established or in the conservation of rare genetic resources. At present it is difficult to see practical applications for embryo transfer and related technologies in tropical small-holder systems.

\section{Conclusion}

The domestic buffalo has unique biological characteristics that distinguish it from cattle. Although some of these attributes have made it an indispensable livestock resource, particularly to smallholder farmers in developing countries, others have been a hindrance to greater exploitation of its potential. Under most small-holder production systems the reproductive efficiency of buffaloes is compromised by factors related to climate, management, nutrition and diseases. Thus the main thrust in improving fertility under such situations is likely to be based on simple but innovative improvements and interventions that alleviate these stresses and, where relevant, on the rational application of modern technologies.

The basic technical problems associated with AI in buffaloes were largely overcome a decade ago but it has failed to have the expected impact, due largely to infrastructural and logistic problems. More advanced approaches such as use of hormones for treating anoestrus and synchronizing oestrus are likely to succeed only after the more basic problems have been rectified. They also demand a good knowledge of the production system in order to be used in a cost-effective manner. Embryo transfer and related technologies will, for the foreseeable future, be applicable only under very specific conditions as in the establishment and multiplication of elite institutional herds, as an alternative to importation of live animals, or for the conservation of germplasm.

\section{References}

Abeygunawardena H, Kuruwita VY and Perera BMAO (1996a) Effects of different suckling regimes on postpartum fertility of buffalo cows and growth rates and mortality of calves. In Role of the Buffalo in Rural Development in Asia pp 321-336 Eds BMAO Perera, JA des Siriwardene, NU Horadagoda and MNM Ibrahim. Natural Resources, Energy and Science Aüthority for Sri Lanka, Colombo

Abeygunawardena H, Subasinghe DHA, Perera ANF, Ranawana SSE, Jayatilake MWAP and Perera BMAO (1996b) Transfer of technology in smallholder intensive buffalo farming: results from a pilot study in Mahaweli System " $\mathrm{H}^{\prime \prime}$. In Role of the Buffalo in Rural Development in Asta pp 67-94 Eds BMAO Perera, JA deS Siriwardene, NU Horadagoda and MNM Ibrahim. Natural Resources, Energy and Science Authority for Sri Lanka, Colombo

Agarwal SK and Purbey LN (1983) Aberrations of the oestrous cycle in rural buffaloes Indian Veterinary Journal 60 989-991

Ahmed N, Chaudry RA and Khan BB (1981) Effect of month and season of calving on the length of subsequent calving interval in Nili-Ravi buffaloes Animial Reprodiction Science 3 301-306

Avenell JA, Seepudin $\mathrm{Y}$ and Fletcher IC (1985) Concentrations of $\mathrm{LH}$, oestradiol $17 \beta$ and progesterone in the peripheral plasma of swamp buffalo cows (Bubalus bubalis) around the time of oestrus Journal of Reproduction and Fertility 74 $419-424$
Barkawi AK, Bedeir LH and El Wardani MA (1993) Sexual behaviour of Egyptian buffaloes in postpartum period Buffalo Jourinal $9225-236$

Batra SK and Pandey RS (1982) Luteinizing hormone and oestradiol $17 \beta$ in blood plasma and milk during the oestrous cycle and early pregnancy in Murrah buffaloes Animal Reproduction Sciance 5 147-157

Bhattacharya P (1974) Reproduction. In The Husbandry and Health of the Domestic Buffalo pp 105-158 Ed. WR Cockrill. FAO, Rome

Bongso TA, Hilmi M and Basrur PK (1983) Testicular cells in hybrid water buffaloes Research in Veferinary Science 35 253-260

Bongso TA, Hassan MD and Nordin W (1984) Relationship of scrotal circumference and testis volume to age and body weight in swamp buffalo Theriogertology 22 127-134

Boni R, Roviello S and Zicarelli L (1996) Repeated ovum pick-up in Italian Mediterranean buffalo cows Theriogenology 46 899-909

Chohan KR, Chaudhry RA, Khan NU and Chaudhry MA (1992) Serum progesterone profile during oestrus cycle and early pregnancy in normal and synchronized Nili-Ravi buffaloes Buffalo Journal $177-82$

Cockrill WR (1974) The Husbandry and Health of the Domestic Buffalo pp 48-56 Ed. WR Cockrill FAO, Rome

Danell B (1987) Oestrous Behaviour, Ovarian Morphology and Cyclical Yariation in Follicular System and Endocrine Pattern 
In Water Buffalo Heifers PhD Thesis Swedish University of Agricultural Sciences, Uppsala

Debenedettia A, Malfatti A, Borghese A, Barile VL and Humblot P (1997) Pregnancy specific protein B (PSPB) detection by RIA in buffalo cows. In Proceedings of the Fifth World Buffalo Congress pp 771-775 Caserta, Italy

de Silva LNA, Perera BMAO, Tilakaratne $\mathrm{N}$ and Edqvist LE (1985) Production Systems and Reproductive Performance of Indigenous Buffnloes in Sri Lanka Swedish University of Agricultural Sciences, Uppsala

Dobson $\mathrm{H}$ and Kamonpatana M (1986) A review of female cattle reproduction with special reference to a comparison between buffaloes, cows and zebu Journal of Reproduction and Ferfility 77 1-36

Drost M, Wright JM, Cripe WS and Richter AR (1983) Embryo transfer in water buffalo (Bubalis bubalis) Theriogenology 20 579-584

Garcia M, Jayasuriya MCN and Perera BMAO (1995) Improving animal productivity by nuclear techniques. In IAEA Yearbook 1995 pp B17-B32 International Atomic Energy Agency, Vienna

Jainudeen MR (1990) A review of embryo transfer technology in the buffalo. In Domestic Buffalo Production in Asia pp 103-112 International Atomic Energy Agency, Vienna

Jainudeen MR and Hafez ESE (1987) Cattle and water buffalo, In Reproduction in Farm Animals (5th Edn) pp 297-314 Ed. ESE Hafez. Lea and Febiger, Philadelphia

Jainudeen MR, Sharifuddin W and Bashir Ahmad F (1983) Relationship of ovarian contents to plasma progesterone concentration in the swamp buffalo (Bubalus bubalis) Veterinary Record 113 369-372

Kamonpatana M, van de Wiel DFM, Koops W, Leenanuraksha LD, Ngramsuriyaroj C and Usanakornkul S (1979) Oestrus control and early pregnancy diagnosis in swamp buffalo: comparison of EIA and RIA for plasma progesterone Theriogenology 11 399-409

Kanai $\mathrm{Y}$ and Shimizu H (1984) Plasma concentrations of LH, progesterone and oestradiol during the oestrous cycle in swamp buffalo (Bubalus bubalis) Journal of Reproduction and Fertility 70 507-510

Kanai Y, Abdul Latief T, Ishikawa N and Shimizu H (1990) Behavioural and hormonal aspects of the oestrous cycle in swamp buffaloes reared under temperate conditions. In Domestic Buffalo Production in Asia pp 113-120 International Atomic Energy Agency, Vienna

Kaur H and Arora SP (1982) Influence of level of nutrition and season on the oestrous cycle thythm and on fertility in buffaloes Tropical Agriculture (Trinidad) 59 274-278

Luktuke SN and Ahuja LD (1961) Studies on ovulation in buffaloes Journal of Reproduction and Fertility 2 200-201

Lundstrom $\mathrm{K}$, Abeygunawardena $\mathrm{H}$, de Silva LNA and Perera BMAO (1982) Environmental influence on calving interval and estimates of its repeatability in the Murrah buffalo in Sri Lanka Animal Reproduction Science 599-109

Madan ML, Das SK and Palta P (1996) Application of reproductive technology to buffaloes Animal Reproduction Science 42 299-306

Mahadevan P (1992) Distribution, ecology and adaptation. In Buffalo Production World Animal Science Series C6 pp 1-12 Eds NM Tulloh and JHG Holmes. Elsevier, Amsterdam

Mohan V, Kuruwita VY, Perera BMAO and Abeygunawardena $\mathrm{H}$ (1990) Effects of suckling on the resumption of postpartum ovarian activity in buffaloes Tropical Agricultural Research 2 306-315
Moioli BM, Napolitano E, Puppo S, Barile VL, Terzano GM, Borghese A, Malfatti A, Catalano A and Pilla AM (1998) Patterns of oestrus, time of LH release and ovulation and effects of time of artificial insemination in Mediterranean buffalo cows Animal Science 66 87-91

Narasimha Rao AV and Venkataramiah P (1989) Luteolytic effect of a low dose of cloprostenol monitored by changes in vaginal resistance in suboestrous buffaloes Animal Reproduction Science 21 149-152

Ohashi OM, Oba E and Nogueira JC (1996) Levels of testosterone and androstenedione in male buffaloes of different ages Buffalo Journal 3 313-320

Pathiraja N, Abeyratne AS, Perera BMAO and Buvanendran V (1979) Fertility in buffaloes after oestrus synchronisation with cloprostenol and fixed time insemination Veterinary Record 104 279-281

Perera BMAO (1980) Hormonal profiles and synchronisation of oestrus in river buffaloes in Sri Lanka. In Animal Production and Health in the Tropics pp 431-434 Eds MR Jainudeen and AR Omar. Penerbit Universiti Pertanian Malaysia, Serdang

Perera BMAO (1987) A review of experiences with oestrous synchronization in buffaloes in Sri Lanka Buffalo Jourmal, Supplement 1 105-114

Perera BMAO (1994) Current buffalo production systems and future strategies for improvement. In Proceedings of Fourth. World Buffalo Congress pp 27-38 Sao Paulo, Brazil

Perera BMAO and Abeyratne AS (1979) The use of nuclear techniques in improving reproductive performance of farm animals World Animal Review (FAO) 32 2-8

Perera BMAO and de Silva LNA (1985) Gestation length in indigenous (Lanka) and exotic (Murrah) buffaloes in Sri Lanka Buffalo fournial 1 83-87

Perera BMAO, Pathiraja N, Kumaratilake WLJS, Abeyratne AS and Buvanendran V (1977) Synchronisation of oestrus and fertility in buffaloes using a prostaglandin analogue Veferinary Record $101520-521$

Perera BMAO, Pathiraja N, Motha MXJ and Weerasekera DA (1979) Seasonal differences in plasma testosterone profiles. in buffalo bulls Theriogenology 12 33-38

Perera BMAO, Pathiraja N, Abeywardena SA, Motha MXJ and Abeygunawardena H (1980) Early pregnancy diagnosis: in buffaloes from plasma progesterone concentration Veterinary Record 106 104-106

Perera BMAO, Abeygunawardena $\mathrm{H}$, Thamotharam $\mathrm{A}$, Kindahl $\mathrm{H}$ and Edqvist LE (1981) Peripartal changes of oestrone, progesterone and prostaglandin in the water buffalo Theriogenology $15463-467$

Perera BMAO, de Silva LNA and Karunaratne AM (1984) Studies on reproductive endocrinology and factors influencing fertility in dairy and draught buffaloes of Sri Lanka. In The Use of Nuclear Techniques to Improve Domestic Buffalo Production in Asia pp 13-28 International Atomic Energy Agency, Vienna

Perera BMAO, de Silva LNA, Kuruwita VY and Karunaratne AM (1987) Postpartum ovarian activity, uterine involution and fertility in indigenous buffaloes at a selected village location in Sri Lanka Animal Reproduclion Science 14 115-127

Perera BMAO, Kuruwita VY, Mohan V, Chandratillake D and Karunaratne AM (1988) Effects of some managerial factors on postpartum reproduction in buffaloes and goats Acfa Veterinaria Scandinavica Supplementa 83 91-100

Rajamahendran $\mathrm{R}$, Jayatilake $\mathrm{KN}$, Dharmawardena J and Thamotharam M (1980) Oestrus synchuronization in buffaloes (Bubalus bubalis) Animal Reproduction Science 3 107-112 
Ranawana SSE, Tilakratne $\mathrm{N}$ and Srikandakumar A (1984) Utilization of water by buffaloes in adapting to a wettropical enyironment. In The Use of Nuclear Tedniiques to Improve Domestic Buffalo Production in Asia pp 171-187 International Atomic Energy Agency, Vienna

Sebastian L, Mudgal VD and Nair PG (1970) Comparative efficiency of milk production by Sahiwal cattle and Murrah buffalo Journal of Animal Science 30 253-256

Sharifuddin W and Jainudeen MR (1983) The accuracy of rectal diagnosis of corpora lutea in water buffalo (Bubalus bubalis) Animal Reproduction Science 6 185-189

Tiwari SR and Pathak MM (1995) Influence of suckling on postpartum reproduction performance of Surti buffaloes Buffalo Journal 2 213-217

Tulloch DG (1979) The water buffalo (Bubalus bubalis) in Australia: reproductive and parent-offspring behaviour Australian Wildlife Research 6 265-287

Usmani RH, Ahmad M, Inskeep EK, Dailey RA, Lewis PE and Lewis GS (1985) Uterine involution and postpartum oyarian activity in Nili-Ravi buffaloes Theriogenology 24 435-448
Usmani RH, Dailey RA and Inskeep EK (1990) Effects of limited suckling and varying prepartum nutrition on postpartum reproductive traits of milked buffaloes fournal of Dairy Science 73 1564-1570

Vale WG (1997) News on reproduction biotechnology in males. In Proceedings Fifth World Buffalo Congress pP 103-123 Caserta, Italy

Vale WG, Ohashi OM, Sousay JS and Ribeiro HFL (1990) Studies on the reproduction of water buffalo in the Amazon basin. In Livestock Reproduction in Latin America pp 201-210 International Atomic Energy Agency, Vienna

Zicarelli L (1997) News on buffalo cow reproduction. In Proceedings Fifth World Buffalo Congress pp 124-141 Caserta, Italy

Zicarelli L, de Filippo C, Francillo M, Pacelli C and Villa E (1997) Influence of insemination technique and ovulation time on fertility percentage in synchronized buffaloes. In Proceedings Fifth World Buffalo Congress pp 732-737 Caserta, Italy 